\title{
Circulatory Recovery Is as Fast With Air Ventilation as With 100\% Oxygen After Asphyxia-Induced Cardiac Arrest in Piglets
}

\author{
RICKARD LINNER, OLOF WERNER, VALERIA PEREZ-DE-SA, AND DORIS CUNHA-GONCALVES
}

Departments of Cardiothoracic Anesthesia and Intensive Care [R.L., D.C.-G.] and Pediatric Anesthesia and Intensive Care [O.W., V.P.-S.], Lund University Hospital, Lund, Sweden SE-22185

\begin{abstract}
We investigated return of spontaneous circulation and of cerebral oxygenation after asphyxia-induced cardiac arrest, using ventilation with air, throughout, or with $100 \%$ oxygen for a shorter or longer period. Arterial pressure, heart rate, regional cerebral oxygen saturation $\left(\mathrm{CrS}_{\mathrm{O} 2}\right)$, and brain tissue oxygen tension $\left(\mathrm{Pbt}_{\mathrm{O} 2}\right)$ were measured in 1-d-old piglets that were hypoventilated with air and left in apnea until cardiac arrest. They were randomly assigned to be resuscitated with air $(n=13)$, or with oxygen for $3(n=12)$ or $30 \mathrm{~min}(n=13)$ and then with air. Nine, 10 , and 10 animals, respectively, needed closed chest cardiac massage. One, none, and one, respectively, died. Median (quartile range) times from start of ventilation until heart rate reached $150 \mathrm{bpm}$ were 67 (60-76), 88 (76-126), and $68(56-81)$ s. They were not significantly different, nor were the arterial pressure responses, times until $\mathrm{CrS}_{\mathrm{O} 2}$ reached $30 \%$, or times until $\mathrm{Pbt}_{\mathrm{O} 2}$ had increased by $0.1 \mathrm{kPa}$ from its nadir. Peak $\mathrm{Pbt}_{\mathrm{O} 2}$ values during resuscitation were 4.2 (3.3-5.4), $12(6.4-15)$, and 25 (15-36) kPa. Thus, pure oxygen did not accelerate the recovery of circulation or of cerebral oxygenation, while even a brief exposure caused cerebral hyperoxia. (Pediatr Res 66: 391-394, 2009)
\end{abstract}

$\mathrm{T}^{\mathrm{k}}$ he optimal fraction of inspired $\mathrm{O}_{2}\left(\mathrm{FiO}_{2}\right)$ for resuscitation of asphyxiated neonates is still not settled, although clinical and experimental evidences indicate that $21 \%$ is superior to $100 \%$ (1-4). In most of these studies, the time of exposure to pure oxygen exceeded $5 \mathrm{~min}$, and it is unknown whether a very brief exposure to high $\mathrm{FiO}_{2}$ at the start of resuscitation might improve myocardial oxygenation and hasten the return of adequate heart function without causing an organ damage.

In three studies of experimental asphyxia (5-7), arterial pressure was restored as quickly by air ventilation as with $100 \%$ oxygen. However, few of the animals in these studies needed closed chest cardiac massage (CCCM), and the possibility remains that subjects with asphyxia, so severe that CCCM is needed, might be easier to resuscitate with a high $\mathrm{FiO}_{2}$. We tested this in 1-d-old piglets in cardiac arrest caused by severe asphyxia and hypothesized that ventilation with $100 \%$ oxygen would restore heart rate (HR) and arterial pressure faster than would ventilation with air. In addition, return of cerebral oxygenation was analyzed, by measuring regional oxygen saturation $\left(\mathrm{CrS}_{\mathrm{O} 2}\right)$ and brain tissue oxygen

Received March 23, 2009; accepted June 2, 2009

Correspondence: Rickard Linner, M.D., Department of Cardiothoracic Anesthesia and Intensive Care, THIVA, Lund University Hospital, Lund, Sweden SE-221 85; e-mail: rickard.linner@gmail.com

Supported by The Laerdal Foundation, Lund University Hospital, and Lund University Medical Faculty grants. tension $\left(\mathrm{Pbt}_{\mathrm{O} 2}\right)$. The asphyxia was induced by hypoventilation followed by apnea to achieve the high blood $\mathrm{PCO}_{2}$ levels that are characteristic of severe clinical perinatal asphyxia (8).

Because the $\mathrm{Pbt}_{\mathrm{O} 2}$ is relevant to the question whether a high $\mathrm{FiO}_{2}$ after asphyxia might cause brain damage, we extended the recording of brain oxygenation beyond the immediate resuscitation phase. Ventilation with $100 \%$ oxygen was limited to $3 \mathrm{~min}$ in some animals to see whether this could avoid cerebral hyperoxia.

\section{METHODS}

This study was approved by the Animal Ethics Research Committee of Lund University. The animals were cared for and handled in accordance with European Guidelines for Use of Experimental Animals.

Animal preparation. Thirty-eight domestic piglets (12- to 36-h old) were premedicated with intramuscular ketamine $(3 \mathrm{mg})$ and midazolam $(0.4 \mathrm{mg})$. They were weighed and placed in an open heated incubator (Dräger, Lubeck, Germany) where they were kept at normal temperature $\left(38.5-40.0^{\circ} \mathrm{C}\right)$, as assessed with a rectal probe. Pulse oximetric saturation was monitored with a probe on the foreleg (OxiMax N-600. Nellcor, Boulder, CO).

An ear vein was cannulated and anesthesia was induced with i.v. propofol $(4 \mathrm{mg} / \mathrm{kg})$ and remifentanil $(1 \mu \mathrm{g} / \mathrm{kg})$. After topical laryngeal anesthesia with lidocaine, $10-20 \mathrm{mg}$, the trachea was intubated with a cuffed tube, and the lungs were mechanically ventilated. The ventilator (Servo 300, Siemens, Sweden) was set in the pressure-regulated volume-controlled mode with the following settings: $\mathrm{I} / \mathrm{E}$ ratio: $1, \mathrm{FiO}_{2}: 0.21$, tidal volume: $10 \mathrm{~mL} / \mathrm{kg}$, end expiratory pressure: $+5 \mathrm{~cm} \mathrm{H}_{2} \mathrm{O}$, and, initially, ventilator rate: $40 / \mathrm{min}$. Ventilator rate was subsequently adjusted between 30 and 50/min aiming at a $\mathrm{PaCO}_{2}$ of $5-6.5 \mathrm{kPa}$.

Anesthesia was maintained by a continuous infusion of fentanyl, 30 $\mu \mathrm{g} \cdot \mathrm{kg}^{-1} \cdot \mathrm{h}^{-1}$, and midazolam, $0.3 \mathrm{mg} \cdot \mathrm{kg}^{-1} \cdot \mathrm{h}^{-1}$. A solution with $25 \mathrm{~g}$ glucose, 70 mmol sodium, $45 \mathrm{mmol}$ chloride, and $25 \mathrm{mmol}$ acetate dissolved per liter was infused at $10 \mathrm{~mL} \cdot \mathrm{kg}^{-1} \cdot \mathrm{h}^{-1}$. During the preparation and stabilization phases, $2 \mathrm{mg} / \mathrm{kg}$ of vecuronium, a muscular relaxant without anticholinergic effect, was injected i.v. in case of shivering. The right external jugular vein was cannulated and used for drug infusions and fluid replacement. The right and left femoral arteries were cannulated for blood sampling and continuous pressure monitoring (Powerlab monitor, ADInstruments, Hastings, East Sussex, United Kingdom). Three needle electrodes were sutured s.c. to the chest for ECG. The scalp was shaved, and a disposable self-adherent near infrared spectroscopy pediatric probe (Pediatric SomaSensor probe $<40 \mathrm{~kg}$, model SPFB-USA, Somanetics Corporation, Troy, MI) was placed over the left scalp and secured with a fabric net. The probe was connected to a cerebral oximeter (INVOS 5100C Cerebral/Somatic Oximeter, Somanetics Corporation) for measurement of $\mathrm{CrS}_{\mathrm{O} 2}$ by dual wavelength near infrared spectroscopy. The $\mathrm{CrS}_{\mathrm{O} 2}$ was updated every $6 \mathrm{~s}$ and stored in the INVOS Oximeter.

A scalp incision was made to expose the right parietal bone. After drilling a 3-mm diameter hole down to the dura mater, a hollow bolt was screwed into

Abbreviations: BE, base excess; Bpm, beats per minute; CCCM, closed chest cardiac massage; $\mathbf{C r S}_{\mathbf{O} 2}$, regional cerebral oxygen saturation; $\mathbf{F i O}_{2}$, inspired fraction of oxygen; HR, heart rate; MAP, mean arterial pressure; $\mathbf{P b t}_{\mathbf{O} 2}$, brain tissue partial pressure of oxygen 
place. The dura mater was perforated using a bevel, a custom made introducer was placed through the bolt, and a flexible microcatheter probe and a thermocouple probe were advanced $\sim 1 \mathrm{~cm}$ into the brain. The microcatheter probe (LICOX; GMS, Mielkendorf, Germany) contained a polarographic oxygen cell. Both probes were connected to a LICOX CMP monitor to obtain temperature-corrected brain tissue $\mathrm{Po}_{2}\left(\mathrm{Pbt}_{\mathrm{O} 2}\right)$. Measurements were updated every $20 \mathrm{~s}$, and the recordings were stored in a personal computer using the LICOX for PC Software.

Experimental protocol. After the preparation, the piglets were allowed to stabilize for at least $30 \mathrm{~min}$, while we ensured that the $\mathrm{PaCO}_{2}$ reached target and remained stable for $10 \mathrm{~min}$ with fixed ventilator settings. Baseline measurements were then made. Thereafter, vecuronium $(2 \mathrm{mg})$ i.v. was given and asphyxia induced as follows. First, the piglets were hypoventilated with air for $20 \mathrm{~min}$ with respiratory rate set to $5 / \mathrm{min}$. Then, ventilation of the lungs was stopped by disconnecting the ventilator. A 60-mL dead-space (HumidVent Light, Mediplast AB, Sweden) was connected to the endotracheal tube to prevent diffusion of room air into the lungs. Apnea was maintained until cardiac arrest, which was defined as a HR $<50$ beats per minute (bpm) with mean arterial pressure $<25 \mathrm{~mm} \mathrm{Hg}$. Ventilation was resumed one minute after cardiac arrest, and the piglet was randomly assigned to one of three groups: resuscitation with air $(n=13)$, with $100 \%$ oxygen for $3 \mathrm{~min}$ and then with air $(n=12)$, or with $100 \%$ oxygen for $30 \mathrm{~min}$ and then with air $(n=13)$. The ventilator settings were the same as at baseline except, possibly, the $\mathrm{FiO}_{2}$. In some animals, cardiac arrest had not developed after 12 min of apnea, in which case apnea was discontinued and resuscitation was carried out as in the other animals, after random assignment to one of the groups.

The arterial pressure and ECG were assessed by an observer, unaware of the group assignment. If no adequate circulation was present after $30 \mathrm{~s}$ of ventilation, i.v. epinephrine $(10 \mu \mathrm{g} / \mathrm{kg})$ followed by $30 \mathrm{~s}$ of CCCM was given. The arterial pressure was evaluated during the subsequent $30 \mathrm{~s}$, and if circulation had not recovered, a second attempt with epinephrine and $30 \mathrm{~s}$ of CCCM was done. If this, too, was unsuccessful, resuscitation ceased. To prevent atelectasis from anesthesia and muscle paralysis, a lung recruitment maneuver was performed at 3, 30, 45, 105, 165, and $225 \mathrm{~min}$

Table 1. Demographics and findings at baseline

\begin{tabular}{lccc}
\hline & \multicolumn{3}{c}{ Group } \\
\cline { 2 - 4 } & Air & 3 min of $\mathrm{O}_{2}$ & 30 min of $\mathrm{O}_{2}$ \\
\hline Male/female/ & $6 / 7$ & $6 / 6$ & $7 / 4 / 2$ \\
$\quad$ unknown & & & \\
Weight $(\mathrm{kg})$ & $1.5(1.4-1.7)$ & $1.5(1.3-1.6)$ & $1.5(1.4-1.7)$ \\
$\mathrm{CrS}_{\mathrm{O} 2}(\%)$ & $45(43-48)$ & $44(40-46)$ & $44(44-46)$ \\
$\mathrm{Pbt}_{\mathrm{O} 2}(\mathrm{kPa})$ & $2.1(1.7-2.8)$ & $1.8(1.3-2.6)$ & $2.0(1.4-2.5)$ \\
$\mathrm{Heart} \mathrm{rate}(\mathrm{bpm})$ & $140(129-158)$ & $143(135-157)$ & $145(141-192)$ \\
$\mathrm{MAP}(\mathrm{mm} \mathrm{Hg})$ & $58(56-60)$ & $64(55-66)$ & $63(56-69)$ \\
\hline
\end{tabular}

after resumption of ventilation, using pressure-controlled ventilation for $15 \mathrm{~s}$ with an inspiratory pressure of $30 \mathrm{~cm} \mathrm{H}_{2} \mathrm{O}$ and an end expiratory pressure PEEP of $20 \mathrm{~cm} \mathrm{H}_{2} \mathrm{O}$.

Arterial samples were taken at baseline, at the end of asphyxia, i.e., just before resumption of ventilation, and after 2.5, 10, 29.5, 60, 120, and $240 \mathrm{~min}$ of ventilation, respectively. They were analyzed for $\mathrm{Po}_{2}, \mathrm{PCO}_{2}, \mathrm{pH}$, and base excess (BE) on an ABL 700 blood-gas analyzer (Radiometer, Copenhagen, Denmark) with settings adjusted to porcine blood according to a factoryinstalled algorithm.

The piglets were cared for $240 \mathrm{~min}$ after resumption of ventilation.

Assessment of immediate circulatory recovery and recovery of cerebral oxygenation. The speed of circulatory recovery was assessed by measuring the time from start of ventilation until spontaneous HR had increased to 150 bpm. In addition, median curves depicting the early HR and MAP responses were obtained by aligning the individual curves so that the exact times when HR reached $150 \mathrm{bpm}$ coincided. This way, the median curves reflected the typical abruptness with which HR and MAP increased once resuscitation was successful. At any point of time on the curves, data from subjects with ongoing CCCM were excluded from the analysis.

Speed of recovery of cerebral oxygenation was evaluated as the time when $\mathrm{CrS}_{\mathrm{O} 2}$ reached $30 \%$ and time when $\mathrm{Pbt}_{\mathrm{O} 2}$ had increased $0.1 \mathrm{kPa}$ from its nadir. They were obtained to the nearest second, through interpolation.

Analysis of cerebral oxygenation during the first 60 min after resumption of ventilation. Curves depicting group medians of $\mathrm{CrS}_{\mathrm{O} 2}$ and $\mathrm{Pbt}_{\mathrm{O} 2}$ at any given time after resumption of ventilation were drawn. In addition, we assessed in each pig maximal (peak) $\mathrm{CrS}_{\mathrm{O} 2}$ and $\mathrm{Pbt}_{\mathrm{O} 2}$ and the times when these occurred.

Statistics. Between-group differences were assessed by one-way ANOVA on ranks using Sigmastat version 3.1 (Systat Software GmbH, Ekrath, Germany). In case of significance, Dunn's test was used to assess pairwise differences between groups. $p$ values $<0.05$ were considered significant. Values in the text and tables are given as median (quartile range) and were calculated using Microsoft Office Excel 2003 (Microsoft, Redmond, WA).

\section{RESULTS}

Demographics are shown in Table 1 and brain oxygenation, MAP, HR, and blood gases at baseline in Tables 1 and 2 .

The concluding apneic phase of the asphyxia lasted 6 min (5-10 $\mathrm{min})$ [median (quartile range) for all animals] and in the last $30 \mathrm{~s}$ of apnea, MAP was $14 \mathrm{~mm} \mathrm{Hg}(11-19 \mathrm{~mm} \mathrm{Hg}$ ) and HR 12 bpm (2-36 bpm). $\mathrm{CrS}_{\mathrm{O} 2}$ was $15 \%$, the minimum values displayed by the equipment, and $\mathrm{Pbt}_{\mathrm{O} 2}$ was $0.0 \mathrm{kPa}(0.0-0.1$ $\mathrm{kPa})$. None of these measures differed between groups.

In two animals, subsequently resuscitated with air, and in one, subsequently given pure oxygen for $30 \mathrm{~min}$, apnea was

Table 2. Arterial blood-gas values

\begin{tabular}{|c|c|c|c|c|c|c|}
\hline \multirow[b]{2}{*}{ Group } & \multirow[b]{2}{*}{ Baseline } & \multirow[b]{2}{*}{ End asphyxia } & \multicolumn{4}{|c|}{ Time from start of resuscitation (min) } \\
\hline & & & 2.5 & 10 & 29.5 & 60 \\
\hline \multicolumn{7}{|l|}{$\mathrm{pH}$} \\
\hline Air & $7.41(7.36-7.44)$ & $6.69(6.60-6.73)$ & $6.90(6.87-6.93)$ & $6.97(6.86-7.02)$ & $7.14(7.00-7.22)$ & $7.29(7.19-7.36)$ \\
\hline $3 \mathrm{~min}$ of $\mathrm{O}_{2}$ & $7.41(7.32-7.47)$ & $6.70(6.63-6.75)$ & $6.87(6.81-6.90)$ & $6.91(6.85-6.98)$ & $7.09(7.07-7.19)$ & $7.28(7.20-7.37)$ \\
\hline $30 \mathrm{~min}$ of $\mathrm{O}_{2}$ & $7.40(7.38-7.45)$ & $6.65(6.61-6.73)$ & $6.86(6.83-6.93)$ & $6.94(6.87-7.05)$ & $7.12(7.07-7.22)$ & $7.31(7.29-7.35)$ \\
\hline \multicolumn{7}{|l|}{$\mathrm{BE}(\mathrm{mmol} / \mathrm{L})$} \\
\hline Air & $2.5(1.5$ to 7.6$)$ & $-18.9(-21.5$ to -18.3$)$ & $-17.3(-19.5$ to -15.7$)$ & $-16.0(-20.2$ to -12.5$)$ & $-10.7(-17$ to -6.6$)$ & $-5.1(-10.8$ to -0.6$)$ \\
\hline $3 \mathrm{~min}$ of $\mathrm{O}_{2}$ & $1.6(-2.1$ to 5.3$)$ & $-20.4(-22.0$ to -18.4$)$ & $-19.6(-20.1$ to -18.0$)$ & $-18.0(-19.5$ to -15.1$)$ & $-13.0(-14.8$ to -9.7$)$ & $-6.9(-9.8$ to -2.0$)$ \\
\hline $30 \mathrm{~min}$ of $\mathrm{O}_{2}$ & $3.3(0.8$ to 4.0$)$ & $-19.5(-22.7$ to -15.6$)$ & $-16.9(-20.3$ to -14.8$)$ & $-16.2(-19.8$ to -13.8$)$ & $-11.4(-14$ to -8.4$)$ & $-4.2(-6.1$ to -3.4$)$ \\
\hline \multicolumn{7}{|l|}{$\mathrm{PacO}_{2}(\mathrm{kPa})$} \\
\hline Air & $5.9(5.6-6.5)$ & $21.4(20.2-23.8)$ & $10(7.8-14.2)$ & $8.8(8.3-10.2)$ & $6.8(6.1-7.2)$ & $5.9(5.7-6.4)$ \\
\hline $3 \mathrm{~min}$ of $\mathrm{O}_{2}$ & $5.9(5.4-6.2)$ & $19.6(17.3-21.6)$ & $12(9.1-14.4)$ & $9.0(8.1-10.1)$ & $6.6(5.9-7.3)$ & $5.8(5.1-6.0)$ \\
\hline $30 \mathrm{~min}$ of $\mathrm{O}_{2}$ & $5.8(5.6-6.1)$ & $22.0(20.4-23)$ & $11.8(9.1-14.3)$ & $8.4(7.7-9.3)$ & $6.2(6.0-7.2)$ & $5.4(5.0-5.7)$ \\
\hline \multicolumn{7}{|l|}{$\mathrm{PaO}_{2}(\mathrm{kPa})$} \\
\hline Air & $7.6(7.2-8.2)$ & $1.7(1,0-2.2)$ & $9.2(6.4-10.2)$ & $9.3(8.8-9.8)$ & $8.9(8.6-9.5)$ & $8.7(7.8-9.4)$ \\
\hline $3 \mathrm{~min}$ of $\mathrm{O}_{2}$ & $7.8(7.5-8.3)$ & $2.0(1.7-2.3)$ & $34.3(32-43.2)^{*}$ & $9.1(8.3-10.0)$ & $9(7.9-10.0)$ & $8.2(7.2-9.2)$ \\
\hline $30 \mathrm{~min}$ of $\mathrm{O}_{2}$ & $8.3(7.9-8.7)$ & $1.6(1.3-2.0)$ & $33.6(26.2-38.8) *$ & $52.6(45.6-57.4)^{* \dagger}$ & $44.8(37.2-57.4)^{* \dagger}$ & $9.2(8.1-10.1)$ \\
\hline
\end{tabular}

Median (quartile range) for arterial blood gases $\left(\mathrm{pH}, \mathrm{BE}, \mathrm{PaO}_{2}\right.$, and $\mathrm{Paco}_{2}$ ) at baseline, just before resumption of ventilation (end asphyxia), and at various times after start of resuscitation.

* Significant difference compared to group $(p<0.05)$.

$\dagger$ Significant difference compared to group 3 min of $\mathrm{O}_{2}(p<0.05)$. 
discontinued after $12 \mathrm{~min}$ without our criteria for cardiac arrest being met. HR in these was 90, 60, and $70 \mathrm{bpm}$ and MAP 47, 19, and $17 \mathrm{~mm} \mathrm{Hg}$.

Immediate outcome of resuscitation. The number of pigs randomized to resuscitation with air, $3 \mathrm{~min}$ of oxygen, and 30 min of oxygen, were 13,12 , and 13 , respectively. Those pigs requiring $\mathrm{CCCM}$ after the initial $30 \mathrm{~s}$ of resumed ventilation counted 9, 10, and 10, respectively. Of these, two, two, and one pigs required a second and final attempt with CCCM, which failed in one, zero, and zero pigs. Once effective heart action was being reestablished, HR increased very quickly in all three groups: from below $100 \mathrm{bpm}$ to over $200 \mathrm{bpm}$ within $15 \mathrm{~s}$. The pattern was similar for MAP (Fig. 1). One piglet allotted to ventilation with 30 min of oxygen was initially successfully resuscitated, but died at 10 min after resumption of ventilation. There were no significant between-group differences in respect of time to reach a HR of $150 \mathrm{bpm}$, time until $\mathrm{CrS}_{\mathrm{O} 2}$ reached $30 \%$, or time until $\mathrm{Pbt}_{\mathrm{O} 2}$ had increased by $0.1 \mathrm{kPa}$ from its nadir (Table 3).

Blood gases and cerebral oxygenation after resumption of ventilation. In the groups initially ventilated with $100 \%$ oxygen after asphyxia, marked arterial hyperoxemia $34 \mathrm{kPa}$ (30-41 kPa) was seen already by $2.5 \mathrm{~min}$ (Table 2 ), and the median $\mathrm{PaO}_{2}$ remained at this or a higher level until switching to air. $\mathrm{Pbt}_{\mathrm{O} 2}$ peaked at $25 \mathrm{kPa}(15-36 \mathrm{kPa})$, and $\mathrm{CrS}_{\mathrm{O} 2}$ at $92 \%$ (86-94\%) in piglets ventilated with $100 \%$ oxygen for $30 \mathrm{~min}$. The corresponding figures among those ventilated with air only were $4.2 \mathrm{kPa}(3.3-5.4 \mathrm{kPa})$, and $68 \%(61-72 \%)$, that is $\sim 2.2 \mathrm{kPa}$ and $23 \%$ more, respectively, than at baseline (Table 1). The group ventilated with $100 \%$ oxygen for $3 \mathrm{~min}$ was intermediate in respect of peak $\mathrm{Pbt}_{\mathrm{O}_{2}}$ and peak $\mathrm{CrS}_{\mathrm{O} 2}: 12 \mathrm{kPa}$ $(6.4-15 \mathrm{kPa})$ and $80 \%(73-87 \%)$. The time to peak $\mathrm{Pbt}_{\mathrm{O}_{2}}$ was $12 \mathrm{~min}(9-14 \mathrm{~min})$ in the air-resuscitated group and $11 \mathrm{~min}$ (10-12 $\mathrm{min})$ in the $30 \mathrm{~min}$ of oxygen group. In the group ventilated with $100 \%$ oxygen for $3 \mathrm{~min}, \mathrm{Pbt}_{\mathrm{O}_{2}}$ reached its peak at $7 \mathrm{~min}(7-11 \mathrm{~min})$ and then rapidly decreased to the same levels as in the air ventilated group (Fig. 2). $\mathrm{CrS}_{\mathrm{O} 2}$ in the same group peaked already at 202 s (180-204 s) (Fig. 2). $\mathrm{PaCO}_{2}$

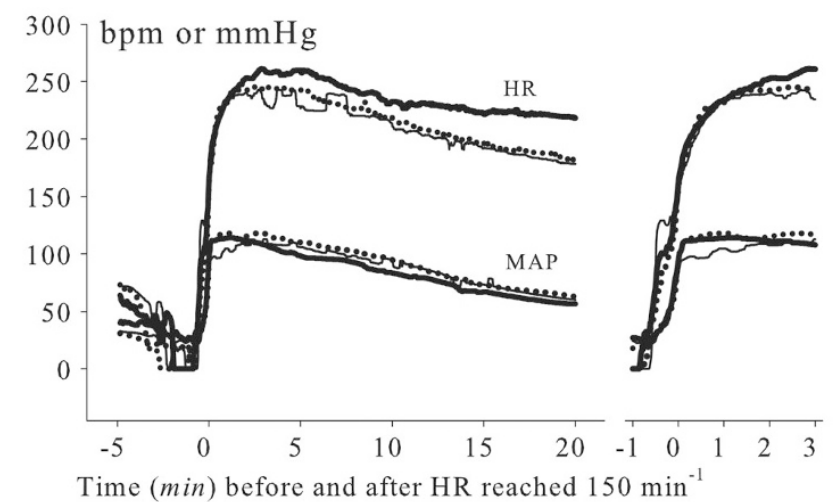

Figure 1. Speed of return of spontaneous circulation among survivors. The curves show group medians of heart rate and arterial pressure at any given time before or after the point when heart rate exceeded $150 \mathrm{bpm}$. The right part of the diagram details the first $3 \mathrm{~min}$. Groups as follows: air ( $n=12$, solid thick line), 3 min of oxygen ( $n=12$, dotted line), and 30 min of oxygen $(n=$ 12 , solid thin line).
Table 3. Resuscitation outcomes

\begin{tabular}{lllr}
\hline \multirow{2}{*}{ Group } & \multicolumn{3}{c}{ Time (s) from start of resuscitation until } \\
\cline { 2 - 4 } & $\mathrm{HR}>150 \mathrm{bpm}$ & $\mathrm{CrS}_{\mathrm{O} 2}>30 \%$ & $\mathrm{Pbt}_{\mathrm{O} 2} \uparrow 0.1 \mathrm{kPa}$ \\
\hline Air & $67(60-76)$ & $72(62-95)$ & $98(88-106)$ \\
3 min of $\mathrm{O}_{2}$ & $88(76-126)$ & $76(68-119)$ & $106(91-121)$ \\
30 min of $\mathrm{O}_{2}$ & $68(56-81)$ & $63(41-75)$ & $92(79-110)$ \\
\hline
\end{tabular}

Median (quartile range) times from resumption of ventilation until heart rate reached $150 \mathrm{bpm}$, regional cerebral oxygen saturation reached $30 \%$, and brain tissue $\mathrm{Po}_{2}$ increased by $0.1 \mathrm{kPa}$ from its nadir.
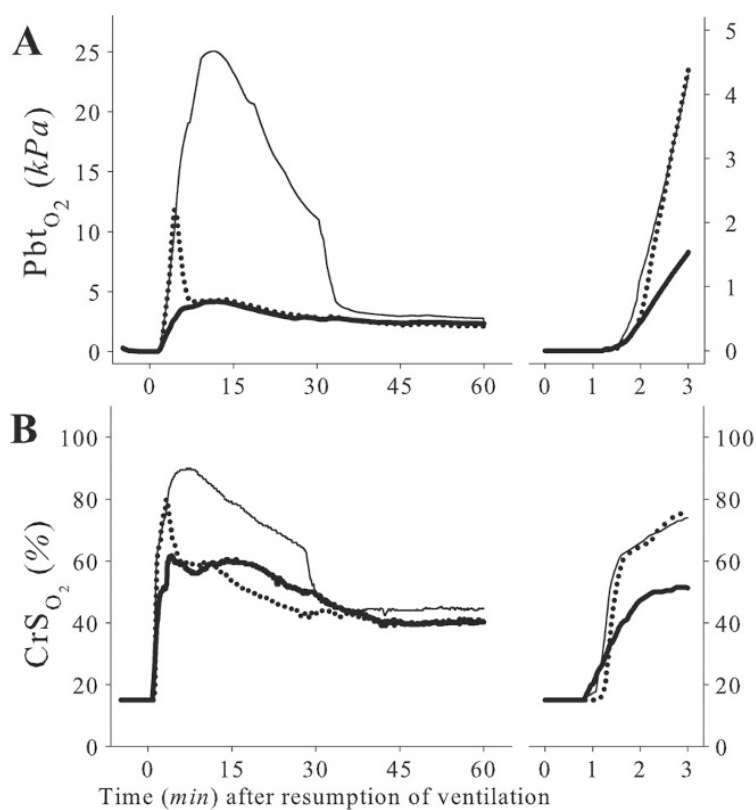

Figure 2. Brain tissue oxygen tension among survivors $(A)$. Curves depict group medians in piglets resuscitated with air $(n=12$, solid thick line $)$, or with 3 or $30 \mathrm{~min}$ of $100 \%$ oxygen followed by air $(n=12$, dotted line and $n=$ 12 solid thin line, respectively). On the right, findings during the first $3 \mathrm{~min}$ of resumed ventilation are shown at increased resolution. Cerebral regional oxygen saturation $(B)$. The minimum value displayed by the measurement equipment was $15 \%$ (see text for other explanations).

decreased on resumed ventilation but was over $8 \mathrm{kPa}$ in most pigs at $10 \mathrm{~min}$.

At 60 min, group medians for $\mathrm{Pbt}_{\mathrm{O} 2}$ and $\mathrm{CrS}_{\mathrm{O} 2}$ (Fig. 2) were similar to baseline (Table 1), as were $\mathrm{PaCO}_{2}$ and $\mathrm{PaO}_{2}$ (Table 2), which remained unchanged throughout the rest of the study. In contrast, arterial $\mathrm{BE}$ and $\mathrm{pH}$ at 60 min were still below baseline (Table 2). At $240 \mathrm{~min}, \mathrm{BE}$ of all animals was +5 mmol/L (1-6 mmol/L), pH 7.45 (7.39-7.47), HR 148 bpm (127-179 bpm), and MAP $54 \mathrm{~mm} \mathrm{Hg}$ (46-60 mm Hg), There was, thus, a slight over-shoot in $\mathrm{BE}$, while $\mathrm{pH}, \mathrm{HR}$, and MAP were at the same levels as at baseline (Tables 1 and 2). There was no significant difference between groups at 60 or $240 \mathrm{~min}$, in respect of any of these measures.

\section{DISCUSSION}

The main finding of this study is that ventilation with $100 \%$ oxygen, instead of air, did not accelerate the return of adequate spontaneous circulation in newborn piglets requiring CCCM for resuscitation from severe asphyxia. Moreover, oxygen ventilation gave very high levels of $\mathrm{Pbt}_{\mathrm{O} 2}$, otherwise seen only under exposure to hyperbaric oxygen (9) and in our previous study on lambs (6). 
The equally fast circulatory recovery with air as with oxygen is in line with results of Fugelseth et al. (10) showing that $100 \%$ oxygen did not decrease myocardial injury as measured by the release of cardiac troponin I (cTnI) in hypoxic piglets. This study differs from theirs, however, in that we studied recovery from cardiac arrest, whereas their animals maintained both HR and cardiac output during the hypoxic event. Another difference is that their animals remained normocarbic, while ours were markedly hypercarbic, a characteristic of severe clinical asphyxia (8).

In this study, $\mathrm{Pbt}_{\mathrm{O} 2}$ peaked at $12 \mathrm{kPa}(6.4-15 \mathrm{kPa})$ and 25 $\mathrm{kPa}(15-36 \mathrm{kPa})$ in piglets resuscitated with oxygen for 3 and $30 \mathrm{~min}$, respectively, whereas in the air ventilated group, the corresponding value was only $4.2 \mathrm{kPa}(3.3-5.4 \mathrm{kPa})$. In contrast, Lyng et al. (11) reported a peak $\mathrm{Pbt}_{\mathrm{O} 2}$ around only 5 $\mathrm{kPa}$ in piglets resuscitated with $100 \%$ oxygen for 30 min after a hypoxic injury with normal $\mathrm{PaCO}_{2}$. We believe that the discrepancies between the studies may largely be explained by the much higher $\mathrm{PaCO}_{2}$ at the end of asphyxia in this study: 21 $\mathrm{kPa}(19-23 \mathrm{kPa})$, and in the study of lambs (6). Although peak $\mathrm{Pbt}_{\mathrm{O} 2}$ in the piglets that we ventilated with oxygen for $30 \mathrm{~min}$ was remarkably high, it was, nevertheless, only about half that in the lambs, perhaps because $\mathrm{Paco}_{2}$ decreased more slowly in the latter. Other possible explanations for the divergent findings are differences in placement of the $\mathrm{Pbt}_{\mathrm{O} 2}$ electrode, degree of injury, and species.

We conclude that ventilation with air restored the circulation as fast as did ventilation with oxygen in piglets resusci- tated after asphyxia-induced cardiac arrest. Thus, resuscitation with an $\mathrm{FiO}_{2}$ of 0.21 should be adequate even in very severe asphyxia, provided the lungs are normal and easy to ventilate. Furthermore, prolonged oxygen ventilation resulted in very high brain tissue oxygen tensions, emphasizing the need to limit oxygen exposure in asphyxiated neonates.

\section{REFERENCES}

1. Saugstad OD, Rootwelt T, Aalen O 1998 Resuscitation of asphyxiated newborn infants with room air or oxygen: an international controlled trial: the Resair 2 study. Pediatrics 102:e1

2. Vento M, Asensi M, Sastre J, Garcia-Sala F, Pallardo FV, Vina J 2001 Resuscitation with room air instead of $100 \%$ oxygen prevents oxidative stress in moderately asphyxiated term neonates. Pediatrics 107:642-647

3. Vento M, Asensi M, Sastre J, Lloret A, Garcia-Sala F, Vina J 2003 Oxidative stress in asphyxiated term infants resuscitated with $100 \%$ oxygen. J Pediatr 142:240-246

4. Saugstad OD, Ramji S, Vento M 2005 Resuscitation of depressed newborn infants with ambient air or pure oxygen: a meta-analysis. Biol Neonate 87:27-34

5. Markus T, Hansson S, Amer-Wahlin I, Hellstrom-Westas L, Saugstad OD, Ley D 2007 Cerebral inflammatory response after fetal asphyxia and hyperoxic resuscitation in newborn sheep. Pediatr Res 62:71-77

6. Perez-de-Sa V, Cunha-Goncalves D, Nordh A, Hansson S, Larsson A, Ley D, Fellman V, Werner O 2009 High brain tissue oxygen tension during ventilation with $100 \%$ oxygen after fetal asphyxia in newborn sheep. Pediatr Res 65:57-61

7. Borke WB, Munkeby BH, Morkrid L, Thaulow E, Saugstad OD 2004 Resuscitation with $100 \% \mathrm{O}(2)$ does not protect the myocardium in hypoxic newborn piglets. Arch Dis Child Fetal Neonatal Ed 89:F156-F160

8. Engle WD, Laptook AR, Perlman JM 1999 Acute changes in arterial carbon dioxide tension and acid-base status and early neurologic characteristics in term infants following perinatal asphyxia. Resuscitation 42:11-17

9. van Hulst RA, Haitsma JJ, Klein J, Lachmann B 2003 Oxygen tension under hyperbaric conditions in healthy pig brain. Clin Physiol Funct Imaging 23:143-148

10. Fugelseth D, Borke WB, Lenes K, Matthews I, Saugstad OD, Thaulow E 2005 Restoration of cardiopulmonary function with $21 \%$ versus $100 \%$ oxygen after hypoxaemia in newborn pigs. Arch Dis Child Fetal Neonatal Ed 90:F229-F234

11. Lyng K, Braakhuis M, Froen JF, Stray-Pedersen B, Saugstad OD 2005 Inflammation increases vulnerability to hypoxia in newborn piglets: effect of reoxygenation with $21 \%$ and $100 \% \mathrm{O}_{2}$. Am J Obstet Gynecol 192:1172-1178 